\title{
Sensitivity Studies on the Impact of Dust and Aerosol Pollution Acting as Cloud Nucleating Aerosol on Orographic Precipitation in the Colorado River Basin
}

\author{
Vandana Jha $\mathbb{D}^{1},{ }^{1,2,3}$ William R. Cotton, ${ }^{3}$ Gustavo G. Carrió, ${ }^{3}$ and Robert Walko ${ }^{4}$ \\ ${ }^{1}$ NASA Ames Research Center, Planetary Systems Branch, Moffett Field, CA, USA \\ ${ }^{2}$ Universities Space Research Association, Houston, TX, USA \\ ${ }^{3}$ Department of Atmospheric Sciences, Colorado State University, Fort Collins, CO, USA \\ ${ }^{4}$ Rosenstiel School of Marine and Atmospheric Science, University of Miami, Miami, FL, USA \\ Correspondence should be addressed to Vandana Jha; vandana.jha@nasa.gov
}

Received 30 August 2017; Revised 4 January 2018; Accepted 31 January 2018; Published 26 March 2018

Academic Editor: Lulin Xue

Copyright (C) 2018 Vandana Jha et al. This is an open access article distributed under the Creative Commons Attribution License, which permits unrestricted use, distribution, and reproduction in any medium, provided the original work is properly cited.

In this study, we examine the cumulative effect of pollution aerosol and dust acting as cloud nucleating aerosol;cloud condensation nuclei (CCN), giant cloud condensation nuclei, and ice nuclei (IN), on orographic precipitation in the Rocky Mountains. We analyze the results of sensitivity studies for specific cases in 2004-2005 winter season to analyze the relative impact of aerosol pollution and dust acting as CCN and IN on precipitation in the Colorado River Basin. Dust is varied from 3 to 10 times in the experiments, and the response is found to be nonmonotonic and depends on various environmental factors. The sensitivity studies show that adding dust in a wet system increases precipitation when IN effects are dominant. For a relatively dry system high concentrations of dust can result in overseeding the clouds and reductions in precipitation. However, when adding dust to a system with warmer cloud bases where drizzle formation is active, the response is nonmonotonic.

\section{Introduction}

This is the second part of a numerical modeling study using Regional Atmospheric Modeling System (RAMS) [13 ] examining the impacts of varying aerosol pollution and dust on precipitation in the Colorado River Basin (CRB). In Jha [4], we examined the combined effect of dust and aerosol pollution on orographic precipitation in the CRB for 2004-2005 winter season. It was found that dust tends to enhance precipitation primarily by acting as IN, while aerosol pollution reduces water resources in the CRB through the "spillover" effect [5-7], by enhancing cloud droplet concentrations and reducing riming rates. It was found that the combined response to dust and aerosol pollution is a net reduction of water resources in the CRB. Here, we perform sensitivity studies to investigate the impacts of dust and pollution aerosol on different kinds of orographic cloud systems depending on different synoptic forcing and availability of moisture. The new RAMS droplet activation code [4] is applied in sensitivity studies of a mixed-phase orographic cloud in northwestern Colorado. Section 2 describes the background work and Section 3 describes the methods and experimental design. The results and comparisons among the three case studies have been discussed in Section 4. The conclusions are offered in Section 5 with a summary of the paper in Section 6.

\section{Background}

The earlier study examines the cumulative effect of dust acting as cloud nucleating aerosol CCN, giant cloud condensation nuclei (GCCN), and ice nuclei (IN) along with anthropogenic aerosol pollution acting primarily as $\mathrm{CCN}$, over the entire Colorado Rocky Mountains from the months of October to April in the year 2004-2005, the snow year. The difference between the old and the new RAMS code has further been discussed. The methods for dust activation as IN in the code, how dust acting as GCCN [8] works in 


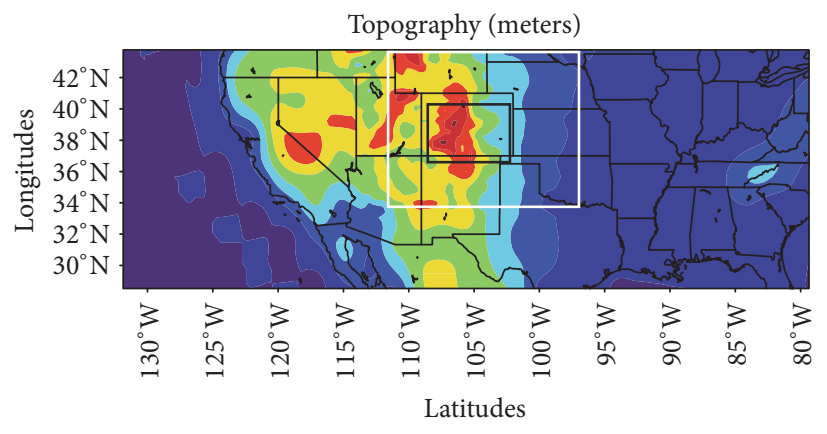

$\begin{array}{llllllll}0 & 500 & 1000 & 1500 & 2000 & 2500 & 3000 & 3500\end{array}$

(a)

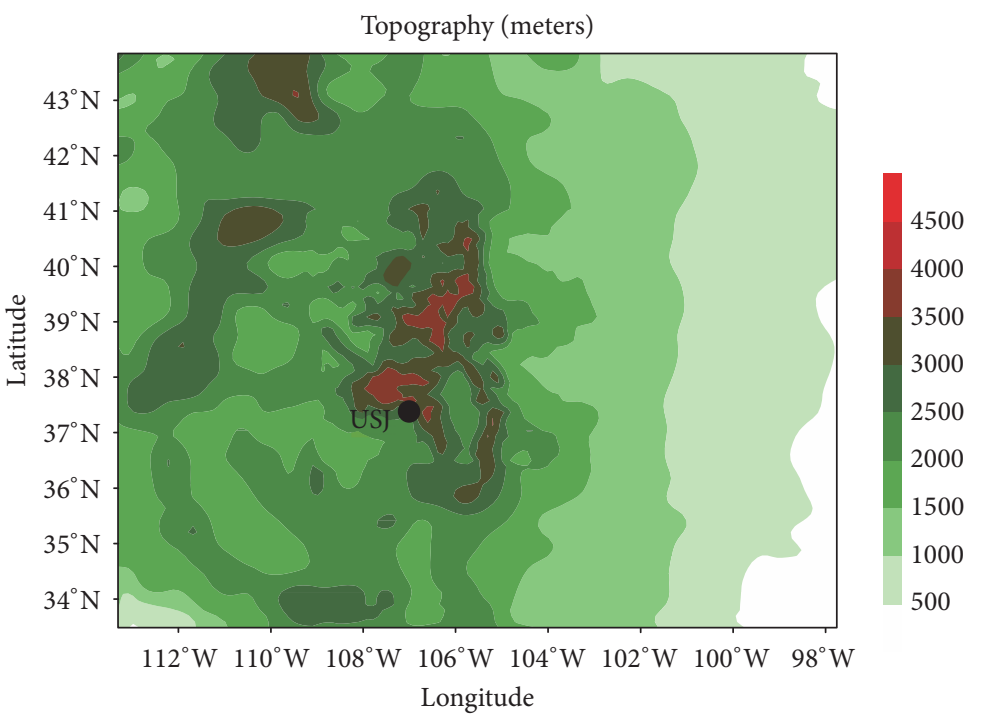

(b)

FIGURE 1: Topography of the area of study where grid 1 is $36 \mathrm{~km}$, grid 2 is $12 \mathrm{~km}$ shown in white rectangle, and grid 3 is $3 \mathrm{~km}$ in black rectangle (a). Topography of grid 3 with USJ $\left(37.49^{\circ} \mathrm{N}, 106.84^{\circ} \mathrm{W}\right)$ marking the Upper San Juan SNOTEL station (b).

RAMS, and how precipitation scavenging is dealt with are described. Letcher and Cotton [9] did a RAMS study on orographic precipitation that suggests that atmospheric CCN concentrations can be reasonably simulated using simplified parameterization of aerosol emissions.

The model setup as well as the initial conditions and the experimental design in the current version of RAMS has also been described in detail in Jha [4]. Kohler theory [10] and its limitations [11] when applied to dust and the corresponding advantages of using the adsorption theory for dust activation scheme have been discussed. In Jha [4], we found that in winter season long simulations, dust primarily acts as IN and increases precipitation over an orographic barrier, but the combined response of dust and pollution aerosols is dominated by the cloud condensation nuclei effects of pollution aerosols which reduced precipitation.

While anthropogenic sources of aerosol particles are changing with human population and technology, natural sources are also impacted. Dust is a relatively large, globally transported natural aerosol source whose production is impacted by the changes to regional climate, especially the hydrologic cycle. Aerosol particles have also been identified to act on cloud microphysics, through the first and second indirect effects [25-27]. Dust aerosol particles have been shown to serve as CCN, GCCN, and IN [16, 28-31]. Therefore, the presence of dust can possibly alter the formation of warm and mixed-phase clouds on the global scale due to the radiative (direct) and the microphysical (indirect) forcings.

In this paper, we analyze the results of sensitivity experiments to study the microphysics of the orographic cloud and their response to varying dust in different cloud regimes. Dust acting as CCN or IN tends to have contrasting impacts when varied in a wet or dry system.

\section{Methods}

In this study, we use the Colorado State University (CSU) Regional Atmospheric Modeling System (RAMS) version 6.0 like Saleeby et al. [32]. The $32 \mathrm{~km}$ North American Regional Reanalysis (NARR) [12] was used for model initialization and 
TABLE 1: RAMS model configuration.

\begin{tabular}{|c|c|}
\hline Model aspect & Setting \\
\hline \multirow{10}{*}{ Grid } & Arakawa C grid [1] \\
\hline & Three grids \\
\hline & Horizontal grid: \\
\hline & grid 1: $\Delta x=\Delta y=36 \mathrm{~km} ; 150 \times 64$ points \\
\hline & grid 2: $\Delta x=\Delta y=12 \mathrm{~km} ; 122 \times 101$ points \\
\hline & grid 3: $\Delta x=\Delta y=3 \mathrm{~km} ; 210 \times 170$ points \\
\hline & Vertical grid: $\Delta z$ variable ( $75 \mathrm{~m}$ at the surface; maximum of $800 \mathrm{~m}$ ) \\
\hline & 35 vertical levels \\
\hline & Model top: $20 \mathrm{~km}$ \\
\hline & 10 levels below $1 \mathrm{~km}$ \\
\hline Initialization & $\begin{array}{l}1^{\circ} \text { GFS data } \\
\text { Soil data initialized with } \sim 32 \mathrm{~km} \text { NARR analyses [12] }\end{array}$ \\
\hline Time step & $30 \mathrm{~s}$ \\
\hline Simulation duration & 10 days for each case study \\
\hline Microphysics scheme & $\begin{array}{l}\text { Two-moment bin-emulating microphysics [13-15] } \\
\text { Water species: vapor, cloud1 and cloud2 cloud drops, rain, pristine ice, snow, } \\
\text { aggregates, graupel, and hail } \\
\text { DeMott et al. [16] heterogeneous ice nucleation and new lookup table including } \\
\text { adsorption theory for dust [17] }\end{array}$ \\
\hline Aerosol and dust sources & $\begin{array}{l}\text { GEOS-Chem and RAMS regional dust sources; dust sources also present in the } \\
\text { nonanthropogenic control run }\end{array}$ \\
\hline Boundary conditions & $\begin{array}{l}\text { Radiative lateral boundary [18] } \\
\text { Top: rigid lid with a high-viscosity layer aloft to damp gravity waves, by nudging to } \\
\text { large-scale analysis or initial conditions [1] }\end{array}$ \\
\hline Turbulence scheme & $\begin{array}{l}\text { Mellor and Yamada [19]; level } 2.5 \text { scheme on grids 1-3; } \\
\text { Smagorinsky [20]; the Kain and Fritsch [21] cumulus parameterization applied to } \\
\text { grids } 1 \text { and 2; convection was resolved explicitly on grid } 3\end{array}$ \\
\hline Radiation scheme & Harrington [22], with additions from Stokowski [23] \\
\hline Surface scheme & LEAF-3 [24] \\
\hline
\end{tabular}

boundary nudging of the geopotential height, temperature, relative humidity, and winds on grid 1 . The initialization data " $1{ }^{\circ}$ GFS" is used for model initialization on all grids and for nudging the fields on grids 1 and 2 . Figure 1(a) shows the 3grid configuration with filled colors showing the topography. Domain 1 is $36 \mathrm{~km}$ and is the entire map, domain 2 is $12 \mathrm{~km}$ and is shown by the white box, and domain 3 is the smallest grid with a $3-\mathrm{km}$ spacing shown by black rectangle in the map. Table 1 summarizes the features of the RAMS setup for this study. A look-up table is designed to simulate the competitive interaction of three externally aerosol species: dust, sea spray salt, and ordinary natural soluble aerosol or pollution aerosol. For dust, which is large and largely insoluble, Koehler theory is replaced by an adsorption theory treatment [17]. For given environmental conditions, water adsorption effects on the insoluble dust particles can produce important reductions in the critical size and therefore significantly affect competition. In order to interface the RAMS droplet activation look-up tables with GEOS-Chem [33] for pollution or clean background (no anthropogenic sources) aerosols, the concentration and chemistry (via kappa) are derived by concentration weighting of three internally mixed groups of aerosols predicted by GEOS-Chem (inorganics, hydrophilic organics, and hydrophobic organics). The kappa and aerosol concentrations so-weighted are then introduced locally to predict the concentration of those potential CCN that are activated to form cloud droplets. In this paper, a series of sensitivity experiments are described to better understand factors influencing the results of impacts of dust and aerosol pollution on seasonal orographic precipitation in the Colorado River Basin [4]. Here we examine specific 10-day periods and perform sensitivity studies to better understand the results from a long term seasonal study. Figure 1(b) shows the topography of the grid 3 with the location of the upper San Juan site in the map $\left(37.49^{\circ} \mathrm{N}\right.$, $\left.106.84^{\circ} \mathrm{W}\right)$.

In these sensitivity studies, dust concentration was multiplied three times and ten times, respectively, in both the RAMS source dust and the GEOS-Chem ingested dust. As summarized in Table 2, sensitivity experiments included a base study (Experiment \#1) in which all dust sources are turned OFF, and only the GEOS-Chem estimated anthropogenic hygroscopic aerosol sources turned ON. Experiment \#2 has both the dust and aerosol pollution data ON. Experiment \#3 has the aerosol sources ON with dust multiplied by a factor of 3, and Experiment \#4 has the aerosol sources 
TABLE 2: Sensitivity tests types.

\begin{tabular}{lccccc}
\hline $\begin{array}{l}\text { Experiment 1 } \\
\text { ald0 }\end{array}$ & $\begin{array}{c}\text { Experiment 2 } \\
\text { ald1 }\end{array}$ & $\begin{array}{c}\text { Experiment 3 } \\
\text { ald3 }\end{array}$ & $\begin{array}{c}\text { Experiment } 4 \\
\text { ald10 }\end{array}$ & $\begin{array}{c}\text { Experiment 5 } \\
\text { aldin }\end{array}$ & $\begin{array}{c}\text { Experiment 6 } \\
\text { aldccn }\end{array}$ \\
\hline Aerosol X1 & Aerosol X1 & Aerosol X1 & Aerosol X1 & Aerosol X1 & Aerosol X1 \\
Dust OFF & Dust X1 & Dust X3 & Dust X10 & $\begin{array}{c}\text { Dust can act } \\
\text { only as IN }\end{array}$ & $\begin{array}{c}\text { Dust can act } \\
\text { only as CCN }\end{array}$ \\
\hline
\end{tabular}

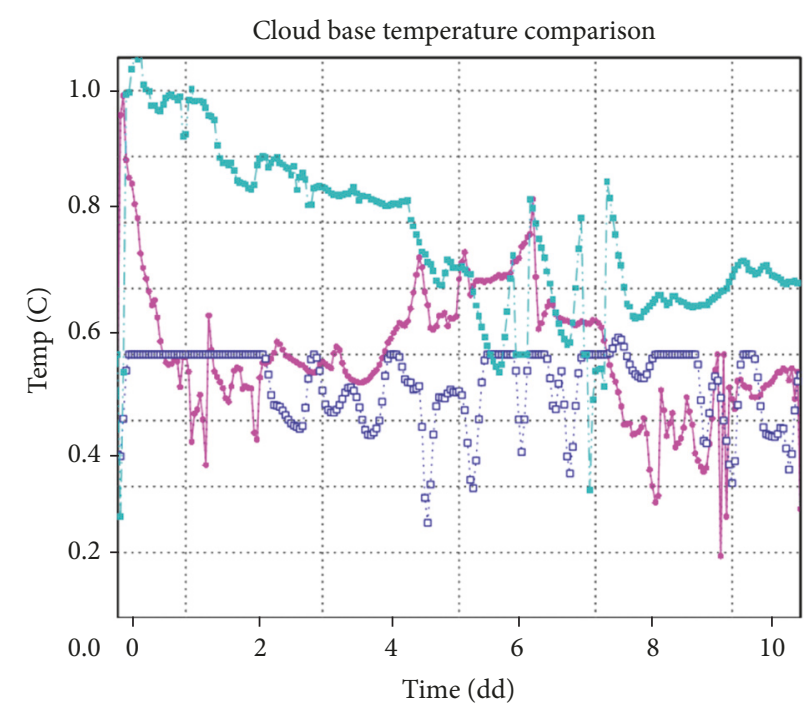

FIGURE 2: Plot of cloud base temperature for the three case studies. Case Study 3 is dominated by lower cloud bases and hence higher cloud base temperatures. Blue: Case Study 1; purple: Case Study 2; green: Case Study 3.

ON with dust multiplied by a factor of 10 . Experiment \#5 is a simulation where dust can act only as CCN, and Experiment \#6 dust acts only as IN.

3.1. GEOS-Chem Model Description. Dust and hygroscopic aerosol data were initialized from the GEOS-Chem model and regional dust sources in RAMS. The GEOS-Chem data represents long range transport of dust, while dust sources in RAMS represent local sources. GEOS-Chem is a global 3-D chemical transport model (CTM) driven by meteorological input from the Goddard Earth Observing System (GEOS) of the NASA Global Modeling and Assimilation Office and is a by-product of the GEOS-5 [33], which includes wind, convective mass fluxes, mixed layer depths, temperature, clouds, precipitation, and surface properties. The aerosol simulation in the GEOS-Chem includes the sulfate-nitrateammonium system $[34,35]$ and carbonaceous aerosol [36, 37]. Dust emissions are estimated using the Ginoux et al. [38] scheme. The dust simulation in GEOS-Chem and dust size distributions are from Fairlie et al. [39] and Zhang et al. [40], respectively. GEOS-Chem is configured with 47 vertical levels and run with a horizontal resolution of $0.5^{\circ} \times$ $0.667^{\circ}$. GEOS-Chem was run with a spin-up of about 1 month. The aerosol species used in this study consist of three inorganic aerosols (sulfate, nitrate, and ammonia), nine organic aerosols (primary hydrophilic organic carbon, primary hydrophilic black carbon, primary hydrophobic organic carbon, primary hydrophobic black carbon), and 5 secondary organic aerosol (SOA) groups, and dust. These sensitivity experiments are performed for the RAMS using adsorption theory, updated look-up tables, and the DeMott et al. [41] IN nucleation scheme. GEOS-Chem is used to estimate nonanthropogenic and anthropogenic pollution contributions to CCN concentrations.

\section{Results and Discussion}

4.1. Case Study 1. Case Study 1 was chosen to examine the impact of changing dust on a relatively wet system typical of the main winter periods in the Colorado Mountains. During this period cloud bases were on an average lower than Case Study 2 but higher than Case Study 3 (Figure 2). Cloud base height is defined as the height of the cloud above the mean sea level. Cloud base temperature is defined as the temperature of typical cloud bases in a region. Thus, higher cloud bases correspond to lower cloud base temperatures and vice versa. Hence, it is hypothesized that ice-phase precipitation can be enhanced for low cloud base height by increasing dust acting as IN. In this first case study, the model was run for a period of 10 days, starting on October 22. The different cases that were run for the same time period are as follows: (a) hygroscopic aerosol ON and dust OFF (ald0), (b) hygroscopic aerosol ON and dust ON (ald1), with both dust and hygroscopic aerosol being from anthropogenic sources and the RAMS regional dust sources being also turned on, (c) hygroscopic aerosol ON and dust multiplied 3 times (ald3), (d) hygroscopic aerosol 


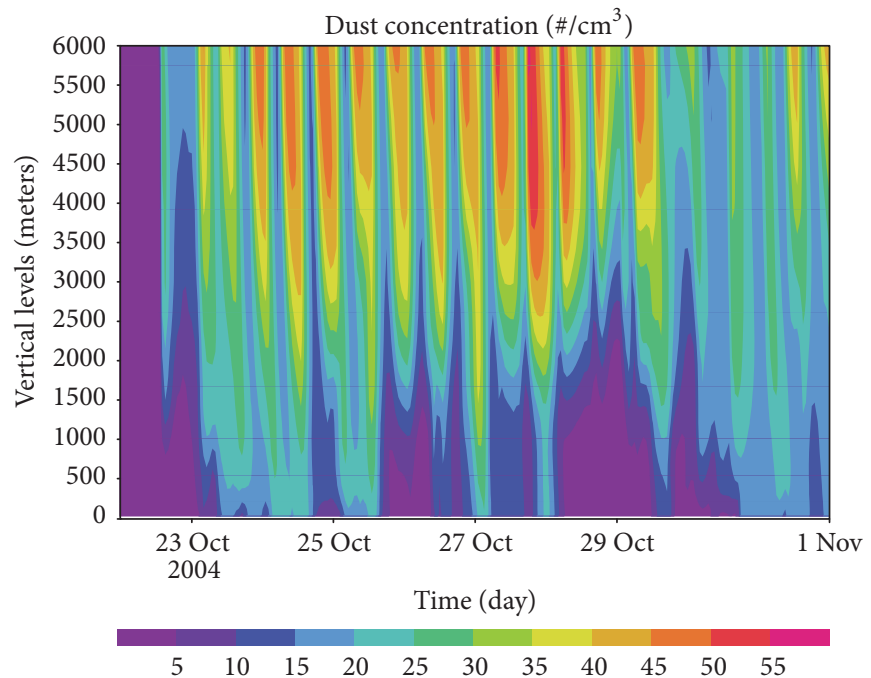

(a)

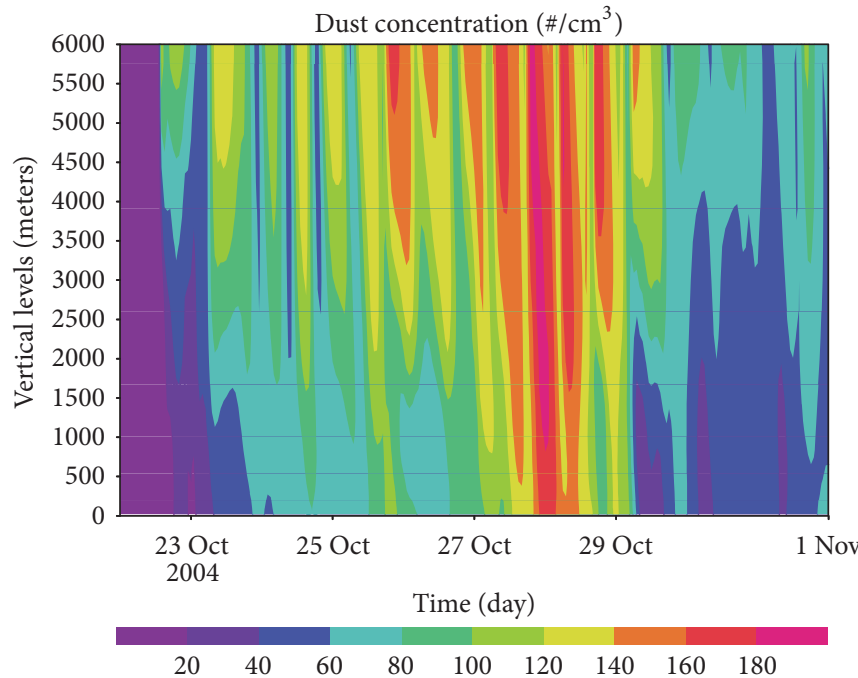

(b)

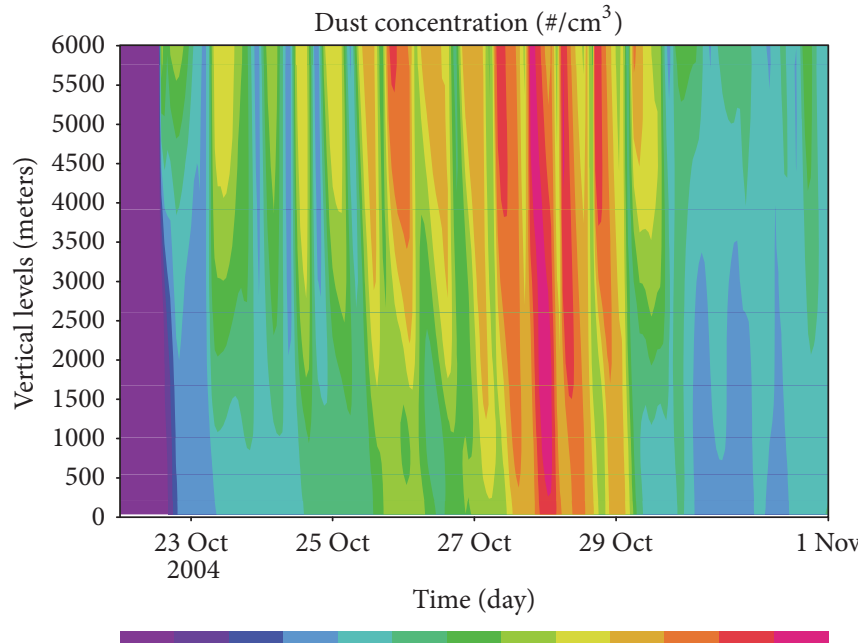

$50 \quad 100150200250300350400450500550600$

(c)

Figure 3: Daily average dust concentration profile for ald1 for Case Study 1 (a); daily average dust concentration profile for ald3 for Case Study 1 (b); daily average dust concentration profile for ald10 for Case Study 1 (c). 


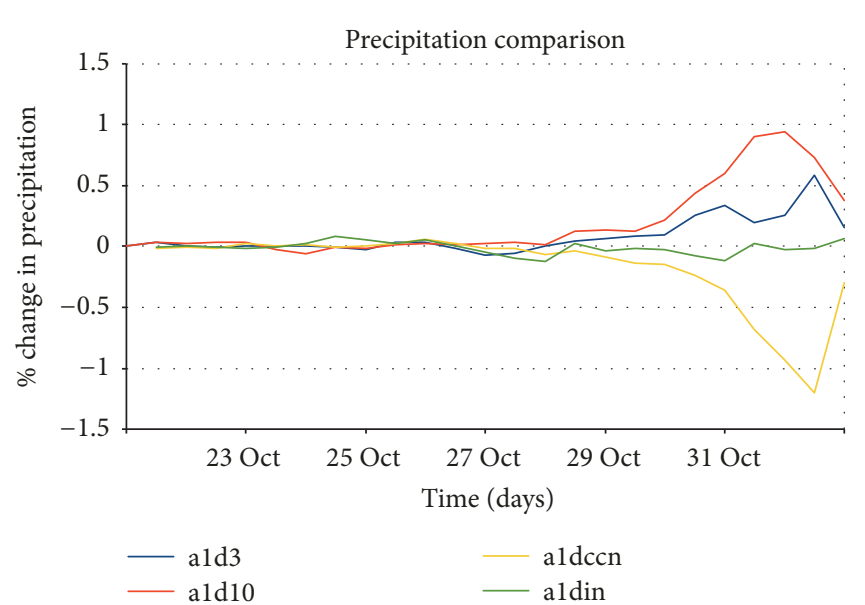

(a)

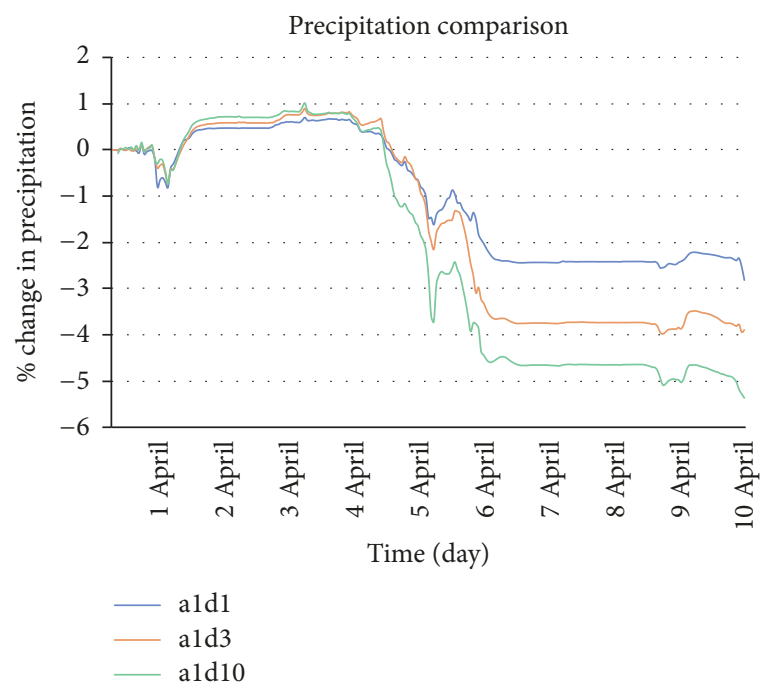

(b)

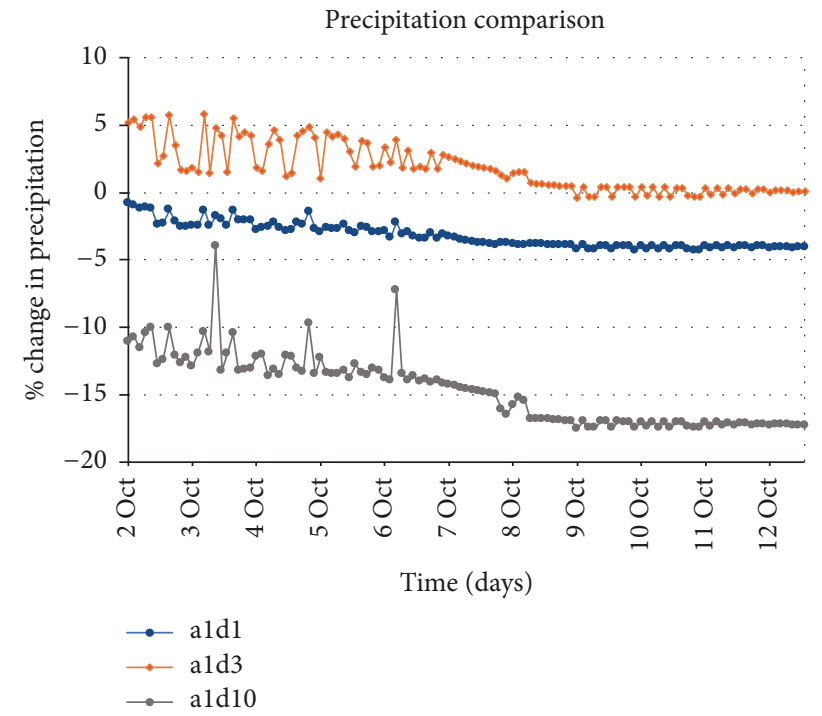

(c)

Figure 4: Plot of precipitation with no dust compared to ald3, ald10, aldccn, aldin for Case Study 1; blue: ald3, red: ald10, green: aldin; yellow: aldin (a). Plot of precipitation with no dust compared to ald1, ald3, ald10; blue: ald1, red: ald3, green: ald10 for Case Study 2 (b). Plot of precipitation with no dust compared to ald1, ald3, ald10; blue: ald1, red: ald3, gray: ald10 for Case Study 3 (c).

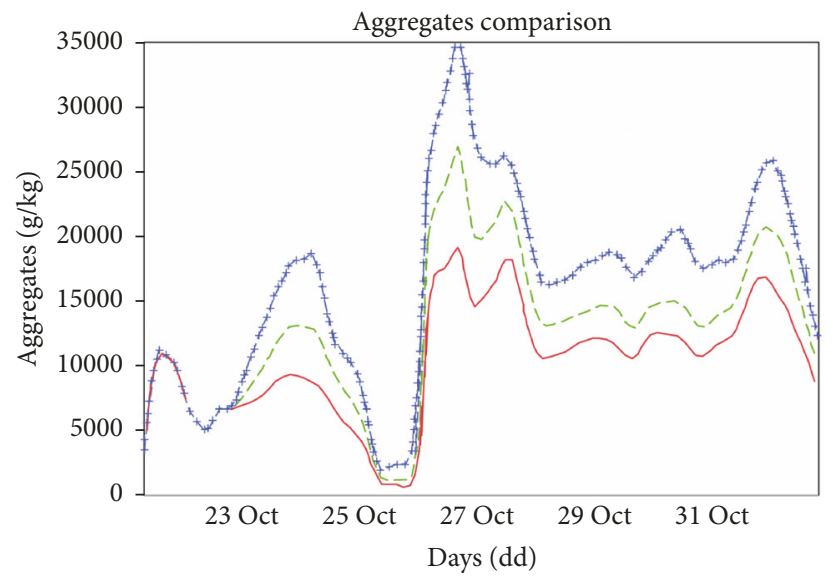

FIGURE 5: Plot of aggregates for the different sensitivity experiments; red: ald1, green: ald3, blue: ald10. 


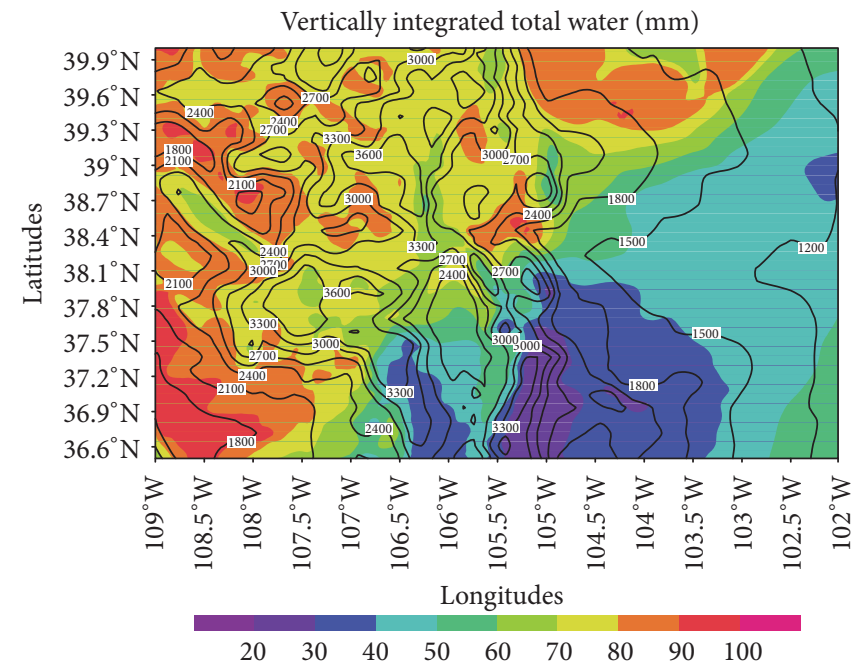

(a)

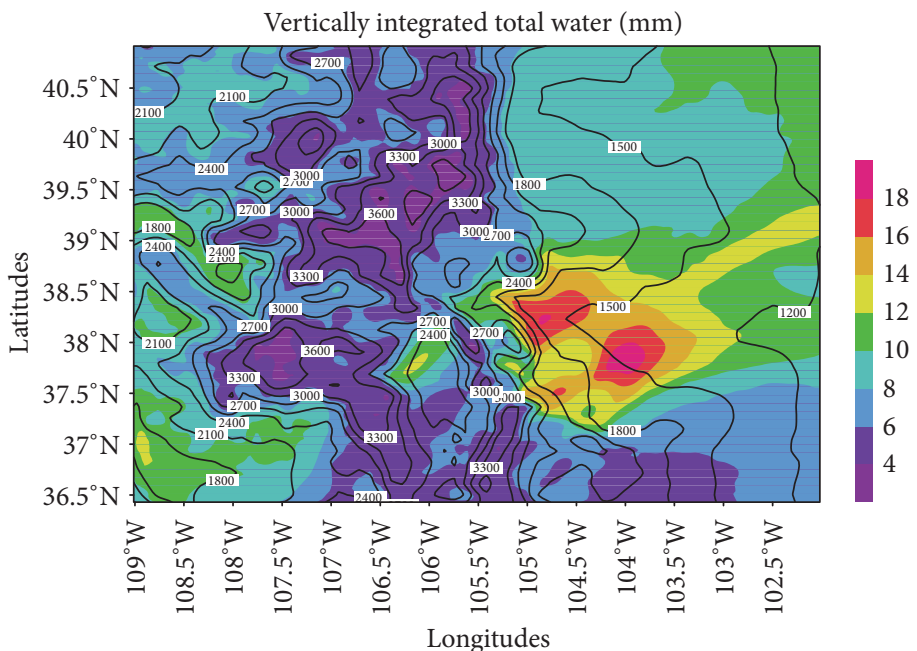

(b)

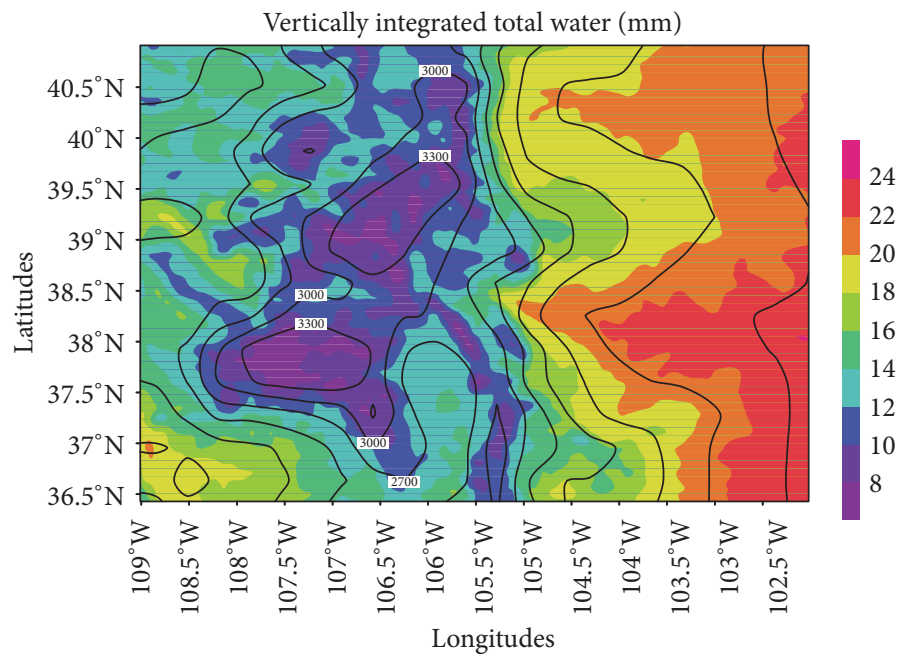

(c)

FIgURE 6: Total precipitable water for grid 3 for Case Study 1 (a); total precipitable water for grid 3 for Case Study 2 (b); total precipitable water for grid 3 for Case Study 3 (c). 


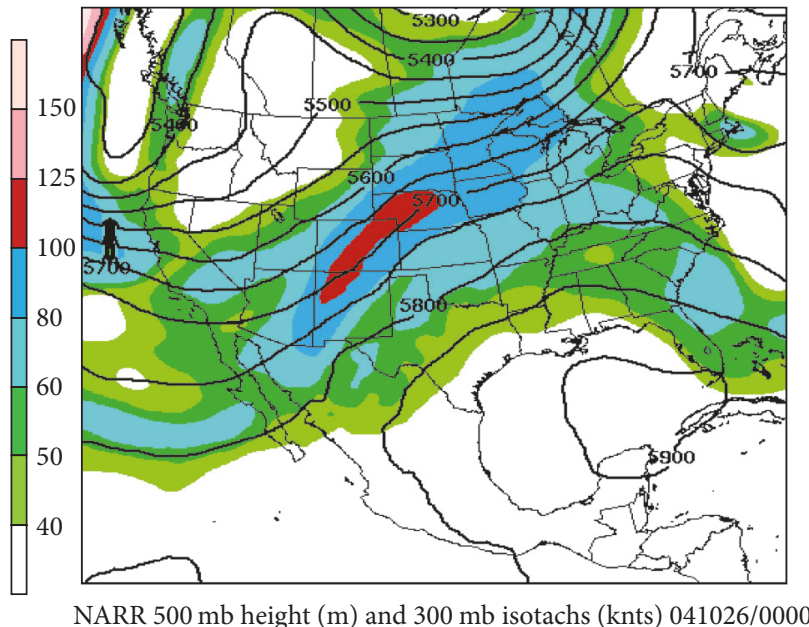

(a)

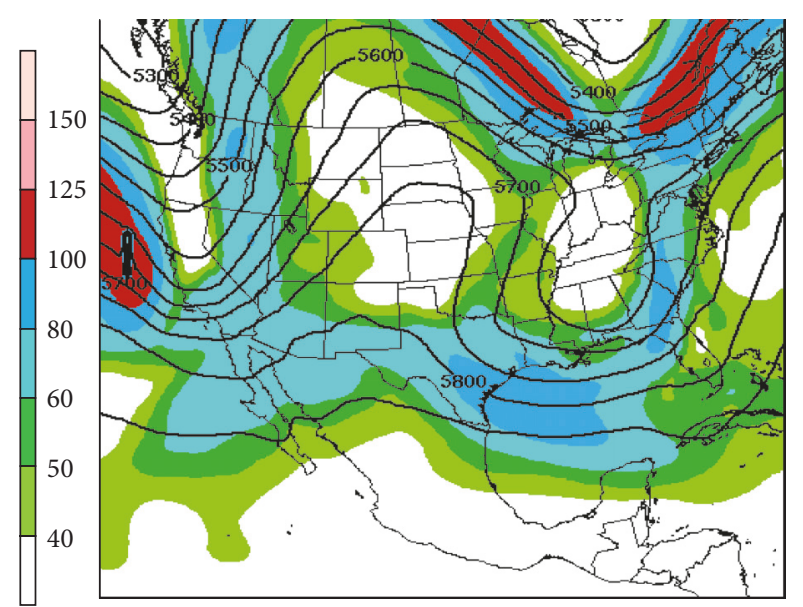

NARR $500 \mathrm{mb}$ height (m) and $300 \mathrm{mb}$ isotachs (knts) 050408/0000

(b)

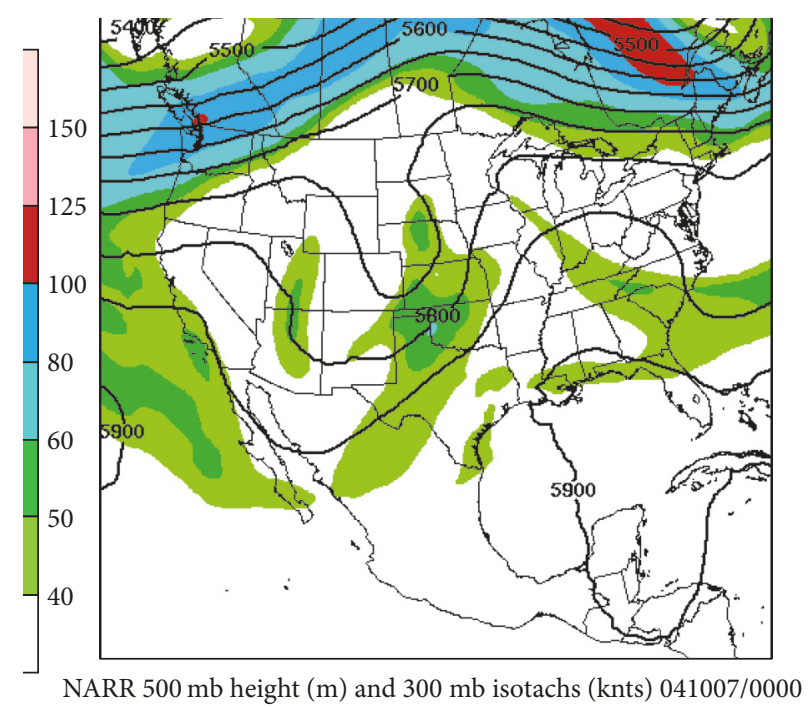

(c)

FIgURE 7: $500 \mathrm{mb}$ geopotential heights for Case Study 1 (a); 500-hPa geopotential height (m) from the NARR dataset for Case Study 2 (b); 500-hPa geopotential height (m) from the NARR dataset for Case Study 3 (c). (Image provided by the NOAA/ESRL Physical Science Division, Boulder Colorado from their Web site at https://www.esrl.noaa.gov/psd/.) In these plots, the $x$ axis is the longitude and $y$ axis is the latitude. The black contour lines are geopotential height contours $(\mathrm{m})$ and the shaded color bars are the isotachs (knots).

ON and dust multiplied 10 times (ald10), (e) dust allowed to act only as CCN (aldccn), and (f) dust allowed to act only as IN (aldin).

It was found that the precipitation increased as the amount of dust in the model was increased from ald0 to ald 1 to ald 3 to ald 10 during this case study period. Figure 3 shows the average daily mean dust concentration for the three different cases (ald1, ald3, and ald10, resp.). The concentration of dust is varied between 10 and $60 \mathrm{~cm}^{-3}$ for ald 1 (Figure 3(a)). In the ald3 dust concentration varies between 10 and $180 \mathrm{~cm}^{-3}$ (Figure $\left.3(\mathrm{~b})\right)$. In the ald10 runs the dust concentration ranges between $10-600 \mathrm{~cm}^{-3}$ (Figure $3(\mathrm{c})$ ). The background pollution aerosol concentration is at values predicted by both GEOS-Chem and RAMS and so varies in space and time for all the cases. Dust acting as CCN tends to decrease precipitation, and dust acting as IN tends to increase precipitation (Figure 4(a)). In this figure the percentage precipitation change relative to each sensitivity run is compared with the control run and shown. Figure 5 shows that there are more aggregates in the ald10 than ald3, and ald1 has the least aggregates. Dust acting as IN leads to the formation of more ice particles; hence it increases the aggregate formation, which roughly varies with the square of ice particle concentrations. The temperature profile indicates that the cloud base temperatures are higher for this system relative to Case Study 2. This is a wet system during this period with more precipitable water available (Figure 6(a)). The $500 \mathrm{mb}$ geopotential height fields indicate a trough moving through the period with light zonal winds (Figure 7(a)). The time series of the snow water equivalent 


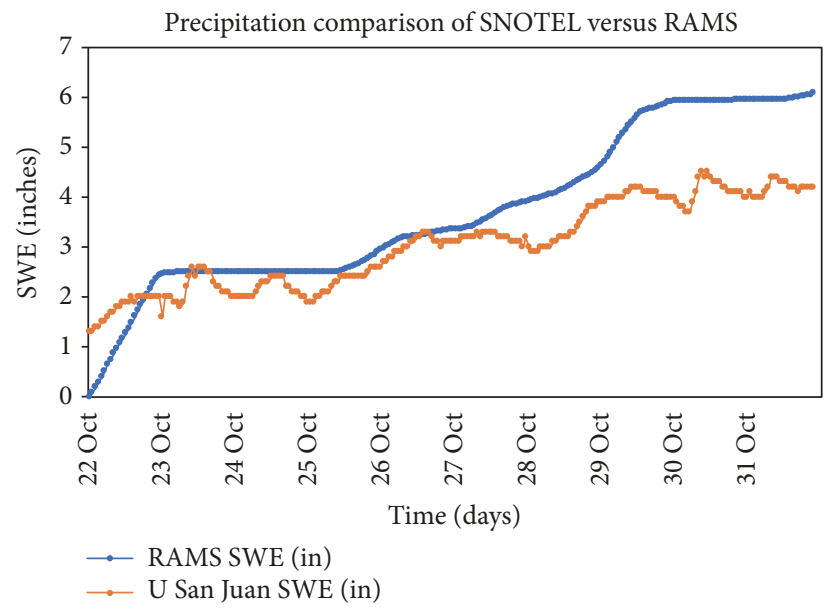

FIGURE 8: Plot for comparison of SNOTEL and RAMS snow water equivalent for Case Study 1. Solid red line: RAMS, crossed green line: SNOTEL.

(SWE) for the seasonal trend of precipitation was compared with SNOTEL site observational measurements. SNOTEL (SNOwpack TELemetry) provides useful high elevation climate information data about real-time precipitation, air temperature, snowpack depth, and snow water content. It makes multiple measurements to provide hourly data per day. SNOTEL uses meteor burst communications technology to collect and communicate data in near-real-time. VHF radio signals are reflected at a steep angle off the ever present band of ionized meteorites existing from about 50 to 75 miles above the earth. We selected SNOTEL sites closest to RAMS grid points and made comparisons with SNOTEL site at San Juan site which is at $\left(37.49^{\circ} \mathrm{N}, 106.84^{\circ} \mathrm{W}\right)$. Figure 8 shows the comparison of model data with the SNOTEL [42] observation data at the upper San Juan site and RAMS for Case Study 1. Simulated precipitation mostly stays in agreement with the observational data, especially during the early part of the period but, not surprisingly, less so during the end of the 10day period.

4.2. Case Study 2. In the second case study, the model was run for a period of 10 days, starting on March 31, 2005, and ending on April 10, 2005. This was a period with higher cloud base heights and is less moist than Case Study 1. The model was run with (a) aerosol ON and dust OFF (ald0), (b) aerosol ON and dust ON (ald1), with both dust and aerosol being from anthropogenic sources and the RAMS regional dust sources being also turned on, (c) aerosol $\mathrm{ON}$ and dust multiplied 3 times (ald3), and (d) aerosol ON and dust multiplied 10 times (ald10). The dust concentration profile is displayed in Figure 9 for the dust ratio aldl, and the background pollution aerosol concentration varies in space and time in accordance with the GEOS-Chem and RAMS estimates including anthropogenic sources for all the cases. Figure 4(b) shows the ratio of precipitation for (a) ald1, (b) ald3, and (c) ald10 with respect to the case when dust was OFF. It was found that precipitation starts decreasing after adding dust to the system at around April 6. The model was run with dust acting as only CCN and IN, and the precipitation for
TABLE 3: Results of dust sensitivities in the three case studies.

\begin{tabular}{|c|c|c|}
\hline \multirow{2}{*}{ Case study } & \multicolumn{2}{|c|}{ Precipitation difference (\%) } \\
\hline & D3-D1 & D10-D1 \\
\hline \multicolumn{3}{|l|}{1} \\
\hline Grid 3 & 0.82 & 2.255 \\
\hline CRB & 0.49 & 1.290 \\
\hline \multicolumn{3}{|l|}{2} \\
\hline Grid 3 & -4.57 & -5.77 \\
\hline CRB & -4.63 & -5.62 \\
\hline \multicolumn{3}{|l|}{3} \\
\hline Grid 3 & 2.718 & -16.907 \\
\hline CRB & 1.642 & -15.560 \\
\hline
\end{tabular}

those two cases was again compared to the NO dust case. It was found that dust acting solely as CCN yields the least precipitation (Figure 10(a)). This was a case with cloud bases colder than Case Study 1 (Figure 2). The precipitable water available for the system was lower than that for Case Study 1 (Figure 6(b)). A major difference between this and Case Study 1 was the very high zonal southwesterly wind right at the period when the transition happened (Figure 11(b)). Case Study $1500 \mathrm{mb}$ zonal winds show moderate winds during the period (Figure 11(a)). The strong wind contributes to precipitation drifting into the subsiding region, or "spillover effect," hence decreasing it. The 500-hPa geopotential height indicates a ridge passing through the region (Figure $7(\mathrm{~b})$ ).

4.3. Case Study 3. The third study was started on October 2 and run for duration of 10 days. Dust was varied in different experiments and pollution aerosol varied spatially and temporally according to GEOS-Chem and RAMS estimates following the pattern in Table 3, and precipitation difference was observed for the duration. This was a period with very warm cloud bases temperatures and lower cloud base height with greater availability of moisture. It is a relatively anomalously 


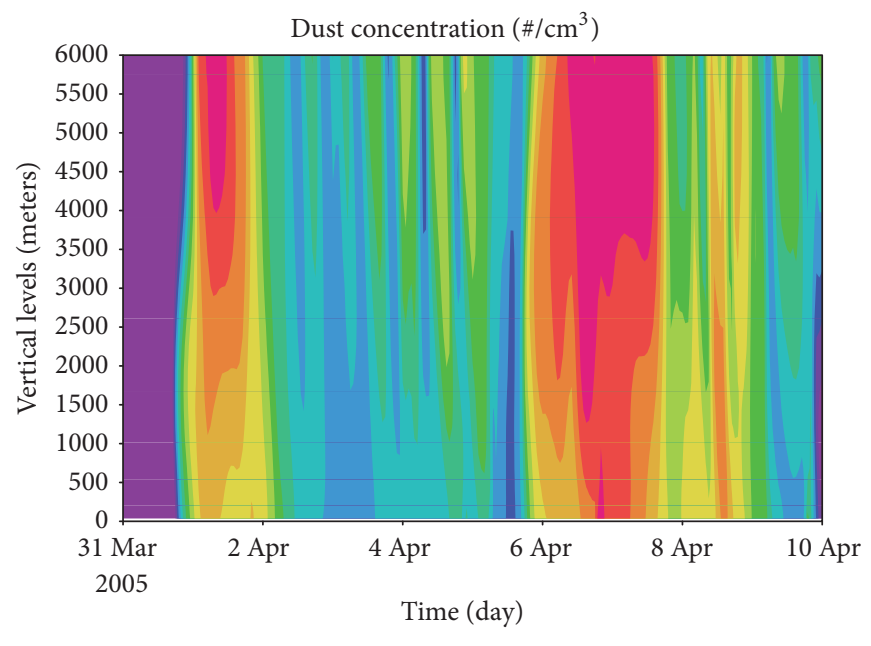

$\begin{array}{llllllllllll}10 & 15 & 20 & 25 & 30 & 35 & 40 & 45 & 50 & 55 & 60 & 65\end{array}$

GrADS: COLA/IGES

FIGURE 9: Daily average dust concentration profile for ald1 for Case Study 2.

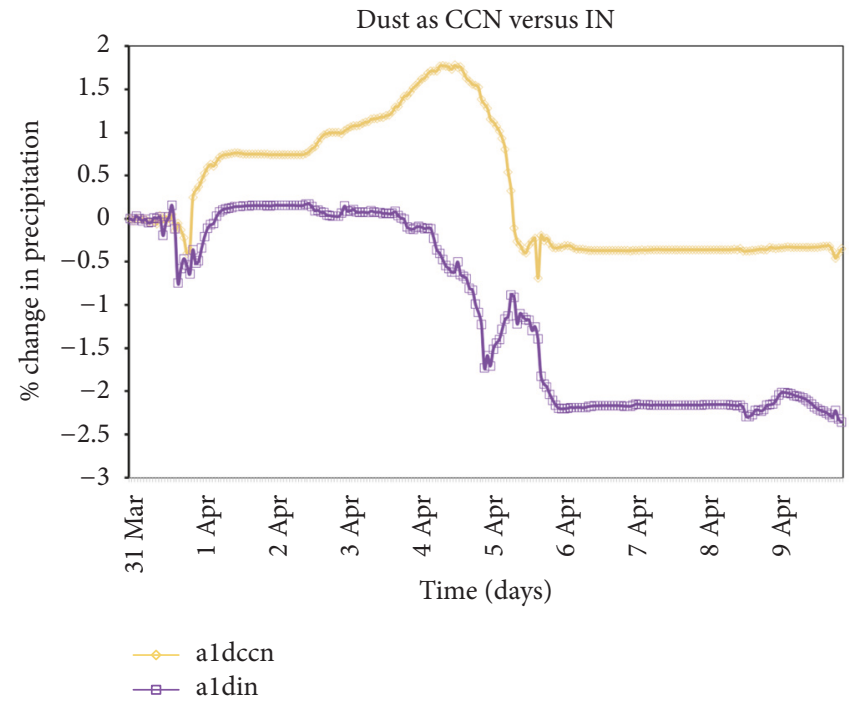

(a)

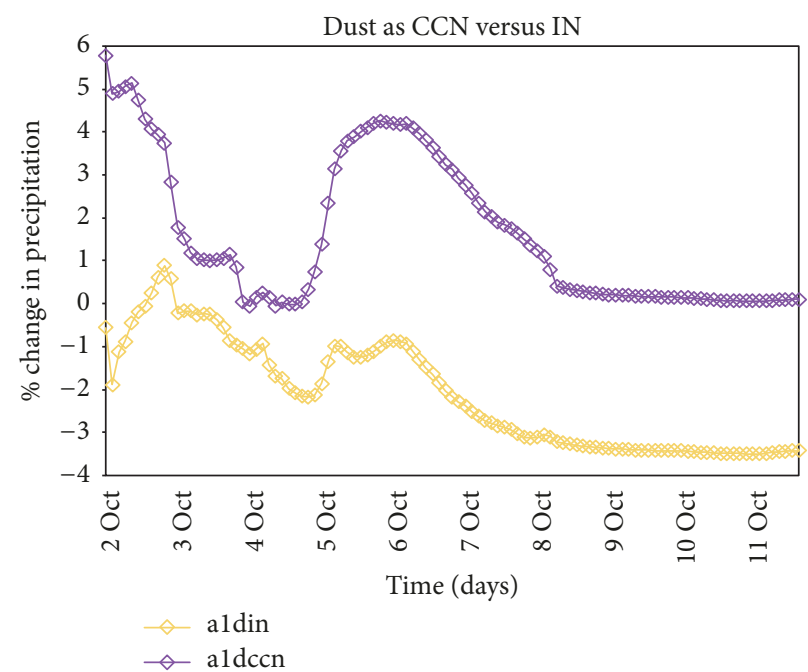

(b)

FIGURE 10: Plot of precipitation with no dust compared to aldecn and aldin; yellow line: aldin; purple line: aldcen (a). Plot of precipitation with no dust compared to dust acting only as IN and CCN; purple: aldccn, yellow: aldin for Case Study 3 (b).

warm cloud base period relative to the main winter season in Colorado. Hence, it is important to see how changing dust impacts precipitation for the period. When dust was increased 3 times, precipitation increased slightly (2.7\%), but when dust was increased 10 times, precipitation decreased by $-16.9 \%$ in the CRB (Figure 12). Figure 4 (c) shows the comparison of the experiments as dust concentration is increased for ald1, ald3, and ald10. The total precipitable water indicated it as a very wet period (Figure 6(c)). When dust is increased 10 times, the precipitation in the system is reduced due to overseeding of IN producing numerous small ice crystals. Figure 13 shows the pristine ice concentrations when dust increased from ald1 (Figure 13(a)) to ald10
(Figure 13(b)). We can see higher concentrations of pristine ice when dust is tenfold. The temperature profile suggests a warmer cloud base as compared to Case Study 1. The system is much wetter than Case Study 2 (Figure 7(c)), and the temperature profile suggests warmer cloud bases in this case compared to the system in both Case Study 1 and Case Study 2 initially (Figure 2). The total mass of the water in the drizzle category reduces with increasing dust, since dust acting as CCN suppresses collision and coalescence [43]. Thus, the availability of supercooled liquid water (SLWC) that could be transferred to snow by riming is increased here (Figure 14). The curve has been normalized by the maximum value. Colder cloud temperatures prevail towards the later part of 


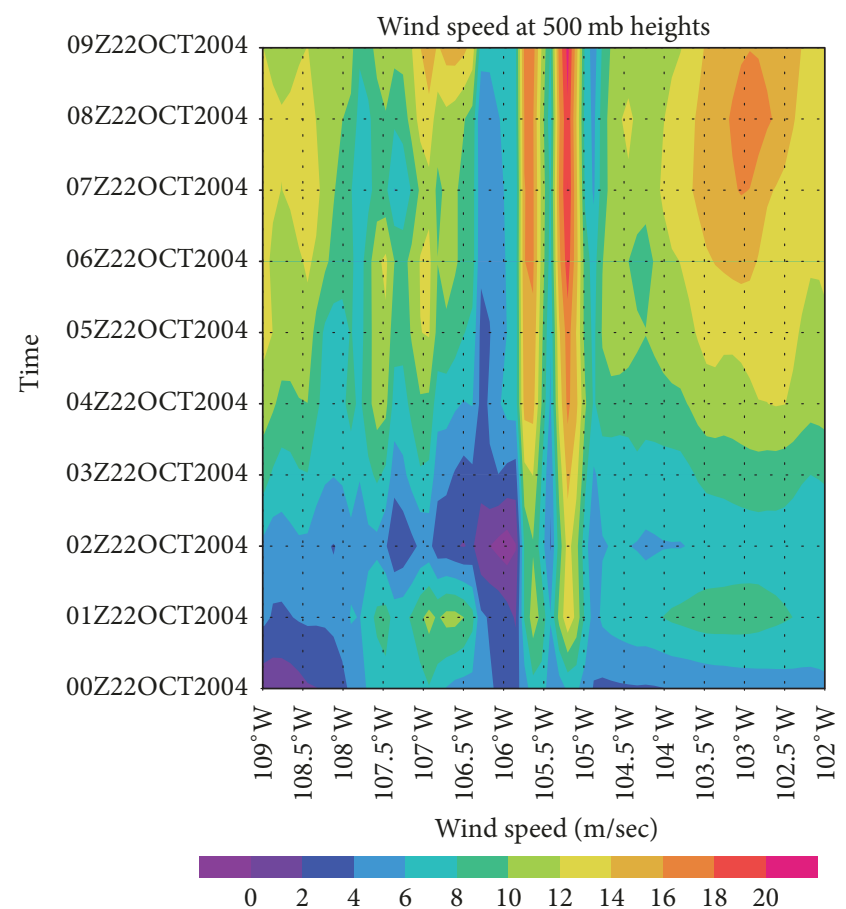

(a)

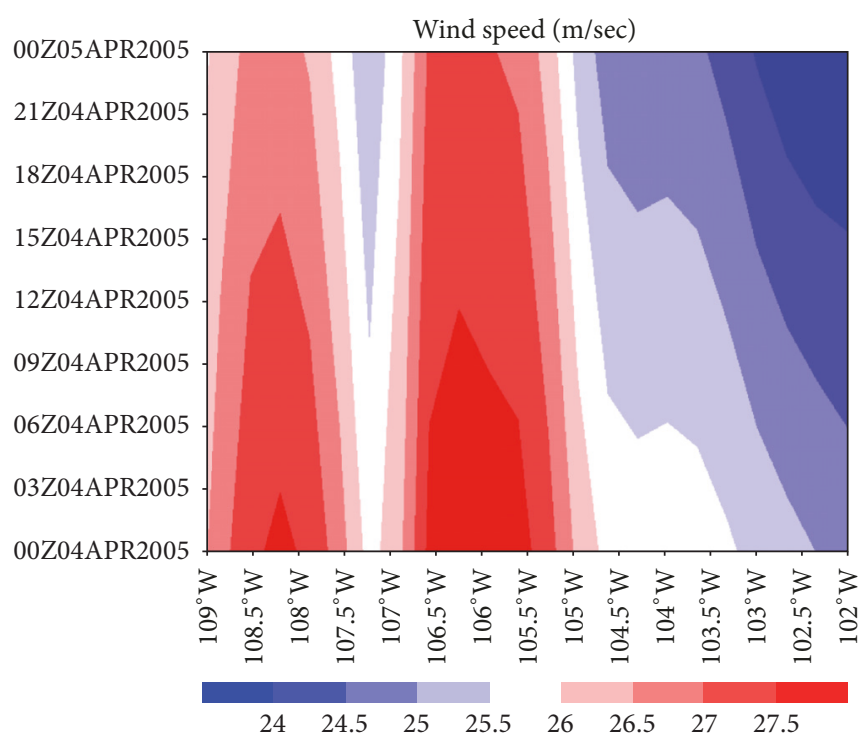

(b)

Figure 11: (a) $500 \mathrm{mb}$ zonal wind speed for Case Study 1 (b). $500 \mathrm{mb}$ zonal wind speed for Case Study 2.

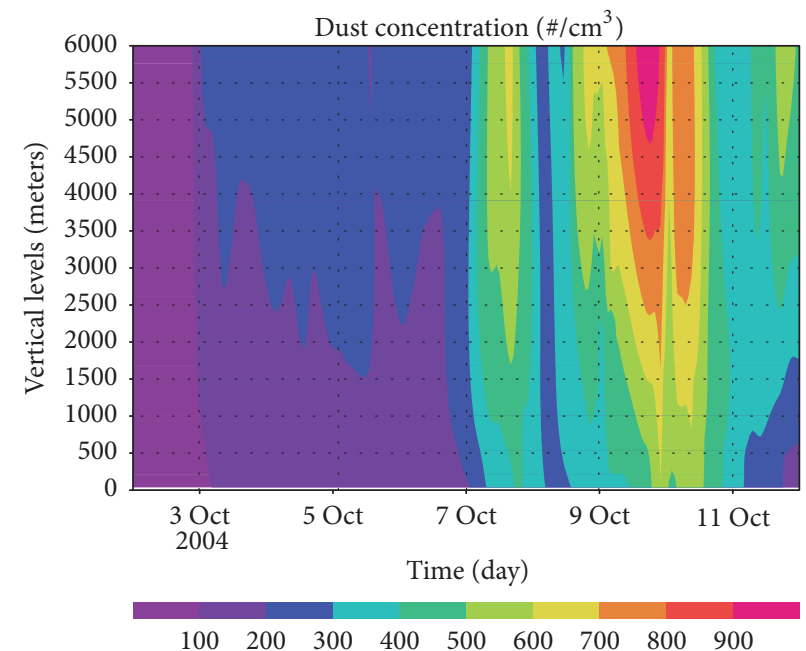

FIGURE 12: Daily average dust concentration profile for ald10 for Case Study 3.

the period, and dust acting as CCN (Figure 10(b)) was more dominant. Despite higher supercooled liquid water contents with higher dust concentrations, high dust concentrations produced numerous small droplets which suppressed riming and led to a reduction in precipitation, a nonmonotonic response when dust is increased 10 times. Carrió and Cotton [44] performed an idealized study and varied both CCN concentrations and the low-level moisture in the Sierra Nevada mountains in a 2D modeling study with RAMS. They observed that for low moisture amounts (i.e., clouds with high cloud bases), increasing CCN decreased the integral mass of snow precipitation. However, for lower cloud bases (higher low-level moisture amounts) or cloud with warmer cloud base, they simulated a nonmonotonic behavior with enhanced ice-phase precipitation.

In a different experiment, other than these three case studies, the model was run to determine the change in response in precipitation between anthropogenic and nonanthropogenic sources of dust and pollution aerosol, and it was found that anthropogenic or nonanthropogenic sources of dust and aerosol pollution have varying impact on the precipitation. In this case, they had a similar response. 


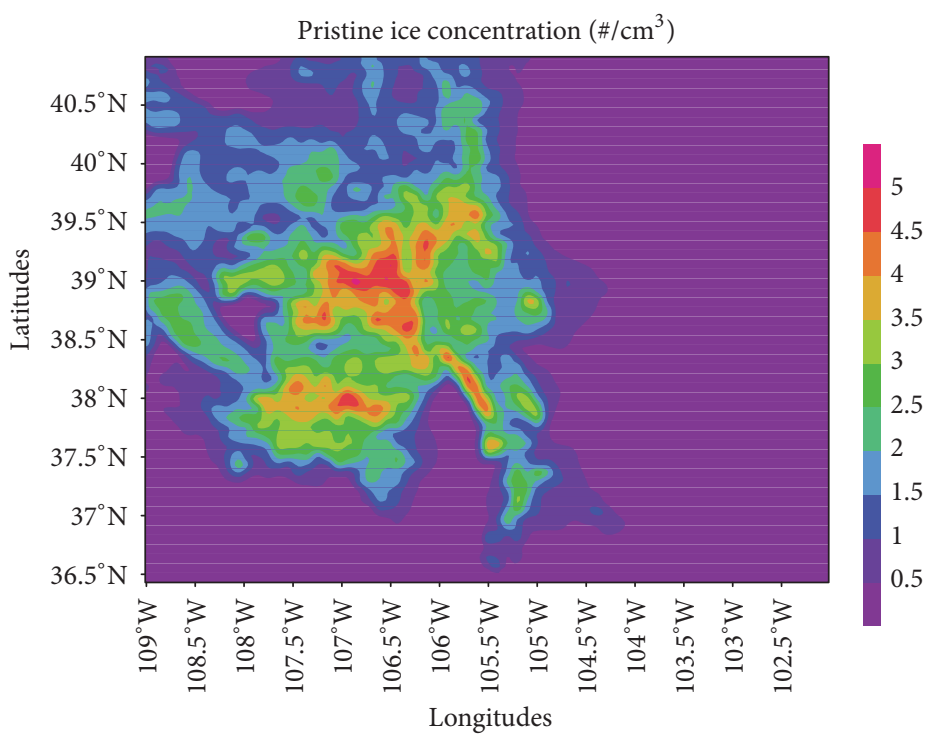

(a)

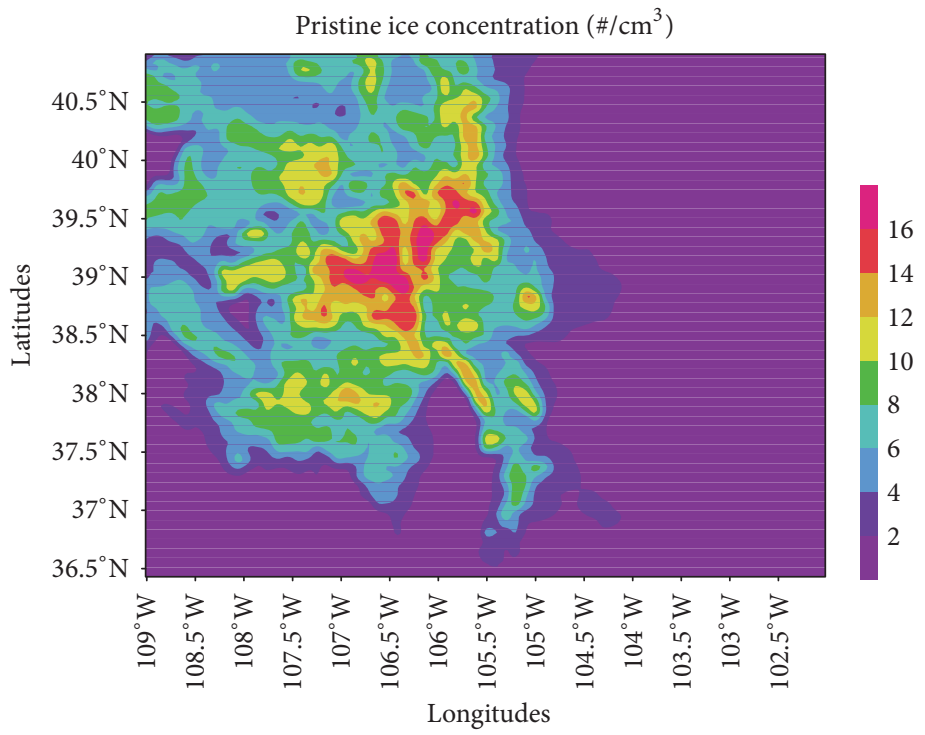

(b)

FIGURE 13: Pristine ice concentration of Case Study 3 for ald1 (a), ald10 (b).

Figure 15 shows the total precipitation response when the model was run for the following cases: (a) aerosol ON and dust ON (ald1), with both dust and aerosol being from anthropogenic sources, (b) aerosol ON and dust ON (ald1), with both dust and aerosol being from nonanthropogenic sources, (c) aerosol ON and dust OFF (a1d0), (d) aerosol $\mathrm{ON}$ and dust multiplied 3 times (ald3), and (e) aerosol $\mathrm{ON}$ and dust multiplied 10 times (ald10). It was found that the precipitation was the highest for the case (e) ald10 and the least for the no dust case (neither anthropogenic nor nonanthropogenic sources). The precipitation for ald3 was less than ald1. However, in yet another case study anthropogenic aerosol had a bigger impact on precipitation (figure not shown here). Hence, it is a nonmonotonic response and we need to do further studies based on other environmental factors and feedback involved.

\section{Discussion}

We performed a series of numerical experiments with the objective of examining the CCN and IN effects and identifying the environmental conditions for which they become dominant. Dust concentration was varied in these three different periods to examine the response on the precipitation in an orographic cloud system. It was found that adding dust in a relatively wet storm (Case Study 1) results in dust increasing precipitation largely due to it acting as IN (Table 3 ). This is due to the greater amounts of supercooled liquid 


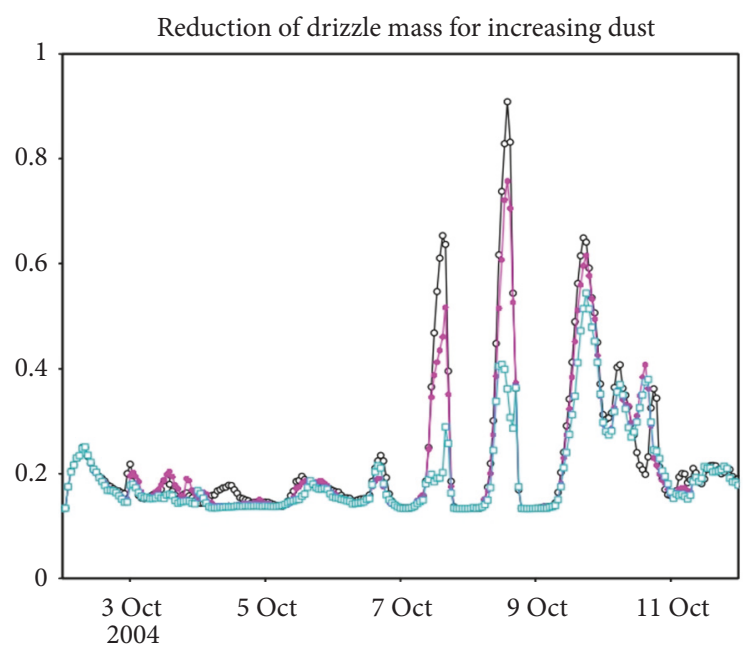

Figure 14: Comparison of total mass of water in drizzle category; black: ald1, pink: ald3, green: ald10.

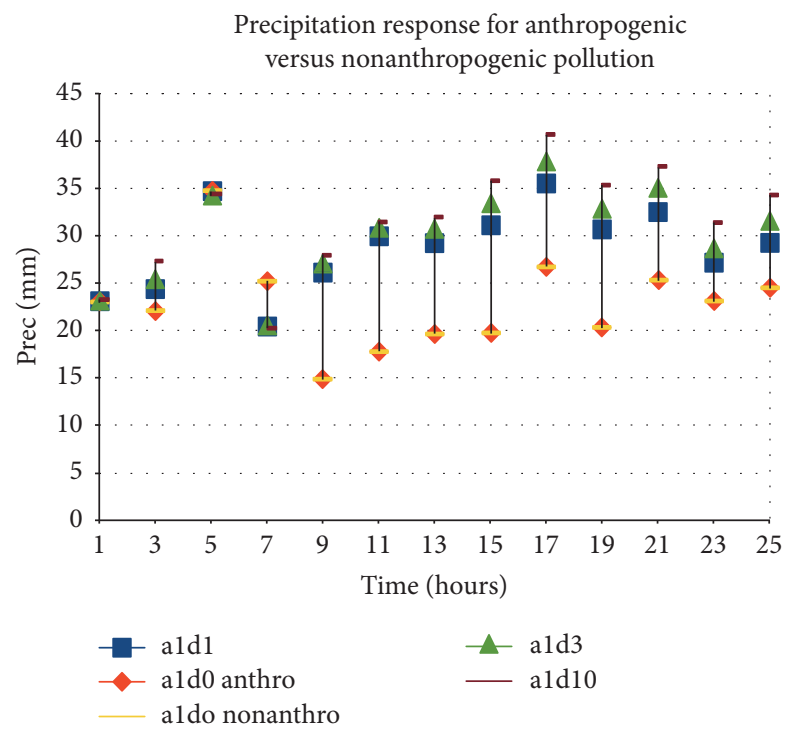

FIGURE 15: Plot of precipitation for (a) ald1, (b) ald0, (c) nonanthropogenic pollution aerosol, (d) ald3, (e) ald10.

water of the system available to enhance precipitation during this period. However, in a relatively dry storm system (Case Study 2), the clouds were "overseeded" with IN, which led to a decrease in precipitation. It is also evident that the background CCN concentration did not play significant role during the sensitivity runs as it remains low throughout the period of change in precipitation. Dust acts as CCN and hence decreases precipitation after April 6 in Case Study 2. Case Study 3 was a period with very warm cloud bases temperatures and lower cloud base heights with greater availability of moisture, which supported an active drizzle formation process. Dust acting as CCN, suppressed drizzle formation and increased SLWC, enhancing riming. The response is not monotonic with dust. The reason is that, for moderate dust concentrations, aerosol pollution dominates

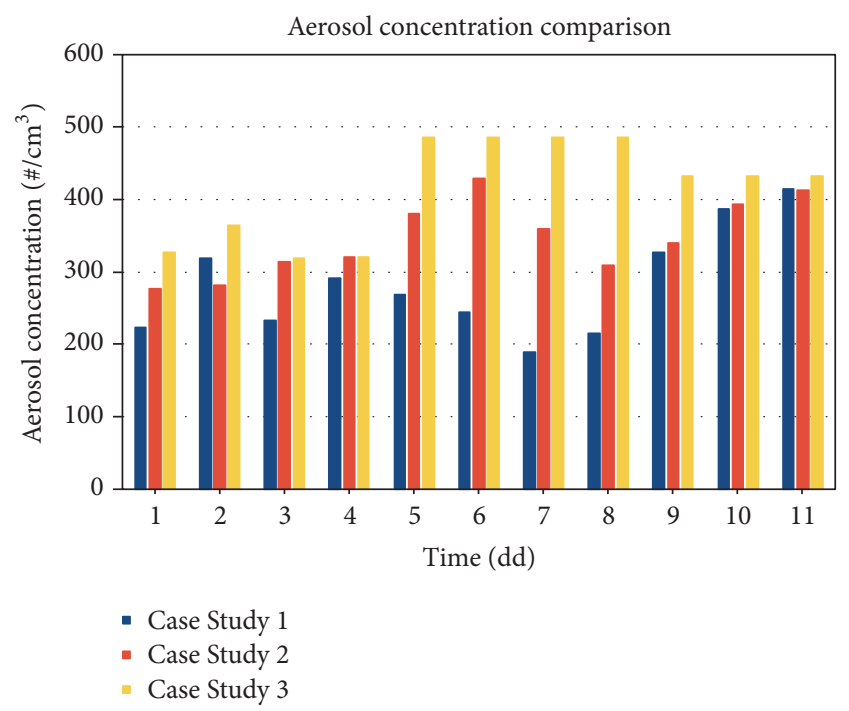

FIGURE 16: Plot of aerosol concentrations for the three case studies. Case Study 3 is the one that has the highest concentration of aerosols.

but, owing to warm cloud bases, drizzle formation is active. For higher concentrations of dust, drizzle acting as CCN suppresses warm rain processes, SLWC increases, and icephase precipitation is enhanced. For dust enhanced 10x, SLWC is enhanced, but riming is suppressed owing to small droplet sizes; therefore, we see lower precipitation amounts in ice-phase when dust is enhanced 10 times in Case study 3 with higher cloud base temperatures. Case Study 3 had also the highest concentration of aerosols as seen in Figure 16.

Changes in microphysics impacts the precipitation of the system, but the dynamical forcing of a storm system which affects wind strength and temperature of cloud base and water content of the storm has a larger impact on the system. More studies need to be done to analyze the response in different cloud regimes and geographical locations.

It is important to keep in mind that results of Jha [4] show that dust is a secondary contributor to precipitation over the CRB as anthropogenic pollution dominates over the entire winter season, contributing total winter season precipitation loss of 5,380,00 acre-feet of water for the $\sim 6.5$ months of simulation.

\section{Summary}

The main conclusions from the results are as follows:

(i) Sensitivity studies suggest that the impact of dust in a system is largely dependent on the synoptic scale flow and the amount of moisture available for a case study. Increasing amounts of dust has a larger impact on wet weather systems.

(ii) In Case Study 1, a wet system, dust increases precipitation in the CRB by $0.49 \%$ when increased 3 times and $1.29 \%$ when increased 10 times. Therefore, in Case 1, the cloud base heights are higher than Case Study 3 and lower than Case Study 2, and adding dust as IN increased precipitation. The dust IN effects are dominant and there is more precipitation when dust acts only as IN, but the increase is not huge. 
(iii) In Case Study 2, dust decreases precipitation in the CRB by $-4.63 \%$ when increased 3 times and $-5.62 \%$ when increased 10 times. This system has the least precipitable water out of the three case studies. Other meteorological factors like high southwesterly wind flow could possibly favor enhanced blow-over of precipitation and hence lead to overseeding of the clouds.

(iv) In Case 3, cloud bases are lower, so the base temperatures are warmer, an active drizzle formation process is present, and dust CCN effects are more dominant. Therefore, we see nonmonotonicity in response and suppression of drizzle formation, which is similar to the results of Carrió and Cotton [44].

\section{Conflicts of Interest}

The authors declare that there are no conflicts of interest regarding the publication of this paper.

\section{Acknowledgments}

This work was supported by the National Science Foundation Division of Atmospheric Sciences Grant AGS 1138896, and the authors are grateful to NSF for this opportunity. The authors want also to thank Dr. Jeffrey Pierce of Colorado State University for providing the GEOS-Chem data.

\section{References}

[1] W. R. Cotton, R. A. Pielke Sr., R. L. Walko et al., "RAMS 2001: current status and future directions," Meteorology and Atmospheric Physics, vol. 82, no. 1-4, pp. 5-29, 2003.

[2] D. G. Lerach, Simulating Southwestern U.S. desert dust influences on severe, tornadic storms [Ph.D. dissertation], Department of Atmospheric Sciences, Colorado State University, 2012.

[3] M. P. Meyers, R. L. Walko, J. Y. Harrington, and W. R. Cotton, "New RAMS cloud microphysics parameterization. Part II: the two-moment scheme," Atmospheric Research, vol. 45, no. 1, pp. 3-39, 1997.

[4] V. Jha, Examination of the potential impacts of dust and pollution aerosol acting as cloud nucleating aerosol on water resources in the Colorado river basin [Ph.D. dissertation], Colorado State University, 2016.

[5] B. Lynn, A. Khain, D. Rosenfeld, and W. L. Woodley, "Effects of aerosols on precipitation from orographic clouds," Journal of Geophysical Research: Atmospheres, vol. 112, no. 10, Article ID D10225, 2007.

[6] S. M. Saleeby, W. R. Cotton, D. Lowenthal, and J. Messina, "Aerosol impacts on the microphysical growth processes of orographic snowfall," Journal of Applied Meteorology and Climatology, vol. 52, no. 4, pp. 834-852, 2013.

[7] A. Muhlbauer and U. Lohmann, "Sensitivity studies of the role of aerosols in warm-phase orographic precipitation in different dynamical flow Regimes," Journal of the Atmospheric Sciences, vol. 65 , no. 8, pp. 2522-2542, 2008.

[8] S. C. van den Heever, G. G. Carrió, W. R. Cotton, P. J. DeMott, and A. J. Prenni, "Impacts of nucleating aerosol on Florida storms. Part I: Mesoscale simulations," Journal of the Atmospheric Sciences, vol. 63, no. 7, pp. 1752-1775, 2006.
[9] T. Letcher and W. R. Cotton, "The effect of pollution aerosol on wintertime orographic precipitation in the colorado rockies using a simplified emissions scheme to predict CCN concentrations," Journal of Applied Meteorology and Climatology, vol. 53, no. 4, pp. 859-872, 2014.

[10] H. Kohler, "The nucleus in and the growth of hygroscopic droplets," Transactions of the Faraday Society, vol. 32, no. 2, pp. 1152-1161, 1936.

[11] P. Kumar, A. Nenes, and I. N. Sokolik, "Importance of adsorption for CCN activity and hygroscopic properties of mineral dust aerosol," Geophysical Research Letters, vol. 36, no. 24, Article ID L24804, 2009.

[12] F. Mesinger, G. DiMego, E. Kalnay et al., "North American regional reanalysis," Bulletin of the American Meteorological Society, vol. 87, no. 3, pp. 343-360, 2006.

[13] S. M. Saleeby and W. R. Cotton, "A large-droplet mode and prognostic number concentration of cloud droplets in the Colorado State University Regional Atmospheric Modeling System (RAMS). Part I: Module descriptions and supercell test simulations," Journal of Applied Meteorology and Climatology, vol. 43, no. 1, pp. 182-195, 2004.

[14] S. M. Saleeby and W. R. Cotton, "A binned approach to clouddroplet riming implemented in a bulk microphysics model," Journal of Applied Meteorology and Climatology, vol. 47, no. 2, pp. 694-703, 2008.

[15] S. M. Saleeby, W. R. Cotton, D. Lowenthal, R. D. Borys, and M. A. Wetzel, "Influence of cloud condensation nuclei on orographic snowfall," Journal of Applied Meteorology and Climatology, vol. 48, no. 5, pp. 903-922, 2009.

[16] C. A. DeMott, C. Stan, D. A. Randall, and M. D. Branson, "Intraseasonal variability in coupled GCMs: The roles of ocean feedbacks and model physics," Journal of Climate, vol. 27, no. 13, pp. 4970-4995, 2014.

[17] P. Kumar, I. N. Sokolik, and A. Nenes, "Measurements of cloud condensation nuclei activity and droplet activation kinetics of fresh unprocessed regional dust samples and minerals," Atmospheric Chemistry and Physics, vol. 11, no. 7, pp. 3527-3541, 2011.

[18] J. B. Klemp and R. B. Wilhelmson, "Simulations of right- and left-moving storms produced through storm splitting," Journal of the Atmospheric Sciences, vol. 35, no. 6, pp. 1097-1110, 1978.

[19] G. L. Mellor and T. Yamada, "A hierarchy of turbulence closure models for planetary boundary layers," Journal of the Atmospheric Sciences, vol. 31, pp. 1791-1806, 1974.

[20] J. Smagorinsky, "General circulation experiments with the primitive equations: I. The basic equations," Monthly Weather Review, vol. 91, pp. 99-164, 1963.

[21] J. S. Kain and J. M. Fritsch, "Convective parameterization for mesoscale models: the Kain-Fritsch scheme," in The Representation of Cumulus Convection in Numerical Models, Meteorological Monographs no. 24, pp. 165-170, American Meteor Society, 1993.

[22] J. Y. Harrington, The effects of radiative and microphysical processes on simulated warm and transition season Arctic stratus [Ph.D. dissertation], Department of Atmospheric Science, Colorado State University, 1997.

[23] D. M. Stokowski, The addition of the direct radiative effect of atmospheric aerosols into the regional atmospheric modeling system (RAMS) [M.S. thesis], Colorado State University, Department of Atmospheric Science, Fort Collins, Colo, USA, 2005.

[24] R. L. Walko, L. E. Band, J. Baron et al., "Coupled atmospherebiophysics-hydrology models for environmental modeling," 
Journal of Applied Meteorology and Climatology, vol. 39, no. 6, pp. 931-944, 2000.

[25] S. Twomey, "Pollution and the planetary albedo," Atmospheric Environment, vol. 8, no. 12, pp. 1251-1256, 1974.

[26] S. Twomey, "The influence of pollution on the shortwave albedo of clouds," Journal of the Atmospheric Sciences, vol. 34, no. 7, pp. 1149-1152, 1977.

[27] B. A. Albrecht, "Aerosols, cloud microphysics, and fractional cloudiness," Science, vol. 245, no. 4923, pp. 1227-1230, 1989.

[28] P. J. DeMott, K. Sassen, M. R. Poellot et al., "African dust aerosols as atmospheric ice nuclei," Geophysical Research Letters, vol. 30, p. 1732, 2003.

[29] P. J. DeMott, O. Möhler, O. Stetzer et al., "Resurgence in ice nuclei measurement research," Bulletin of the American Meteorological Society, vol. 92, no. 12, pp. 1623-1635, 2011.

[30] C. H. Twohy and M. R. Poellot, "Chemical characteristics of ice residual nuclei in anvil cirrus clouds: Evidence for homogeneous and heterogeneous ice formation," Atmospheric Chemistry and Physics, vol. 5, no. 8, pp. 2289-2297, 2005.

[31] C. H. Twohy, S. M. Kreidenweis, T. Eidhammer et al., "Saharan dust particles nucleate droplets in eastern Atlantic clouds," Geophysical Research Letters, vol. 36, no. 1, Article ID L01807, 2009.

[32] S. M. Saleeby, W. R. Cotton, and D. Lowenthal, "Impact of aerosols on the microphysical processes with an orographic cloud environment," in Proceedings of the AMS Annual Meeting, Seattle, Wash, USA, 2011.

[33] I. Bey, D. J. Jacob, R. M. Yantosca et al., "Global modeling of tropospheric chemistry with assimilated meteorology: model description and evaluation," Journal of Geophysical Research: Atmospheres, vol. 106, no. 19, Article ID 2001JD000807, pp. 23073-23095, 2001.

[34] R. J. Park, D. J. Jacob, B. D. Field, R. M. Yantosca, and M. Chin, "Natural and transboundary pollution influences on sulfatenitrate-ammonium aerosols in the United States: Implications for policy," Journal of Geophysical Research: Atmospheres, vol. 109, no. 15, Article ID D15204, 2004.

[35] R. J. Park, D. J. Jacob, N. Kumar, and R. M. Yantosca, "Regional visibility statistics in the United States: Natural and transboundary pollution influences, and implications for the Regional Haze Rule," Atmospheric Environment, vol. 40, no. 28, pp. 5405-5423, 2006.

[36] R. J. Park, D. J. Jacob, M. Chin, and R. V. Martin, "Sources of carbonaceous aerosols over the United States and implications for natural visibility," Journal of Geophysical Research: Atmospheres, vol. 108, no. D12, Article ID D15204, 2003.

[37] H. Liao, D. K. Henze, J. H. Seinfeld, S. Wu, and L. J. Mickley, "Biogenic secondary organic aerosol over the United States: Comparison of climatological simulations with observations," Journal of Geophysical Research: Atmospheres, vol. 112, no. 6, Article ID D06201, 2007.

[38] P. Ginoux, M. Chin, I. Tegen et al., "Sources and distributions of dust aerosols simulated with the GOCART model," Journal of Geophysical Research: Atmospheres, vol. 106, no. 17, pp. 2025520273, 2001.

[39] T. D. Fairlie, D. J. Jacob, and R. J. Park, "The impact of transpacific transport of mineral dust in the United States," Atmospheric Environment, vol. 41, no. 6, pp. 1251-1266, 2007.

[40] L. Zhang, J. F. Kok, D. K. Henze, Q. Li, and C. Zhao, "Improving simulations of fine dust surface concentrations over the western United States by optimizing the particle size distribution," Geophysical Research Letters, vol. 40, no. 12, pp. 3270-3275, 2013.
[41] P. J. DeMott, A. J. Prenni, G. R. McMeeking et al., "Integrating laboratory and field data to quantify the immersion freezing ice nucleation activity of mineral dust particles," Atmospheric Chemistry and Physics Discussions, vol. 14, no. 11, pp. 1735917400, 2014.

[42] Snow Telemetry (SNOTEL) and Snow Course Data and Products, Natural Resources Conservation Service and National Water Climate Center.

[43] J. Peng, Z. Li, H. Zhang, J. Liu, and M. Cribb, "Systematic changes in cloud radiative forcing with aerosol loading for deep clouds in the tropics," Journal of the Atmospheric Sciences, vol. 73, no. 1, pp. 231-249, 2016.

[44] G. G. Carrió and W. R. Cotton, "On the buffering of CCN impacts on wintertime orographic clouds: An idealized examination," Atmospheric Research, vol. 137, pp. 136-144, 2014. 

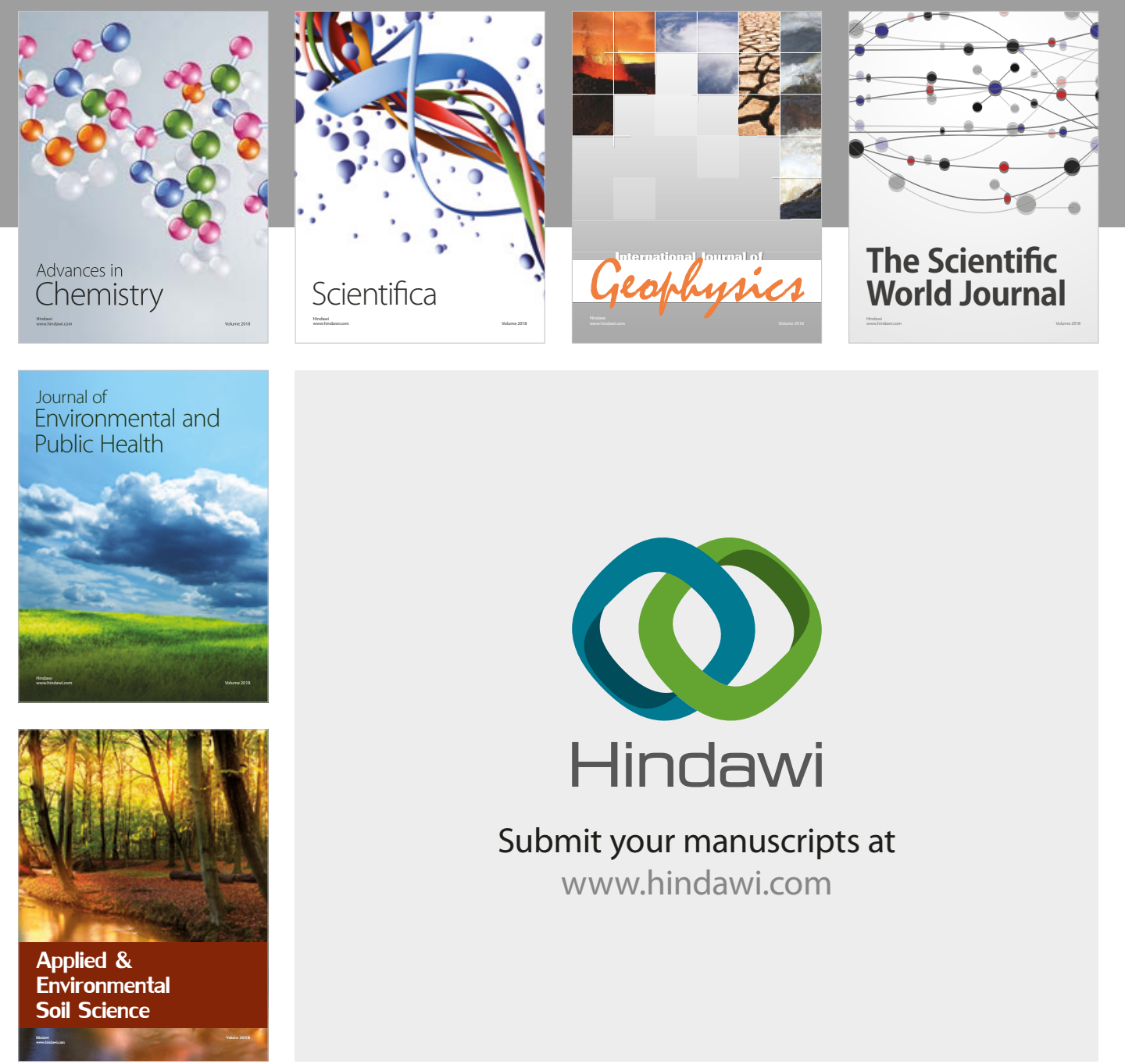

The Scientific

\section{World Journal}
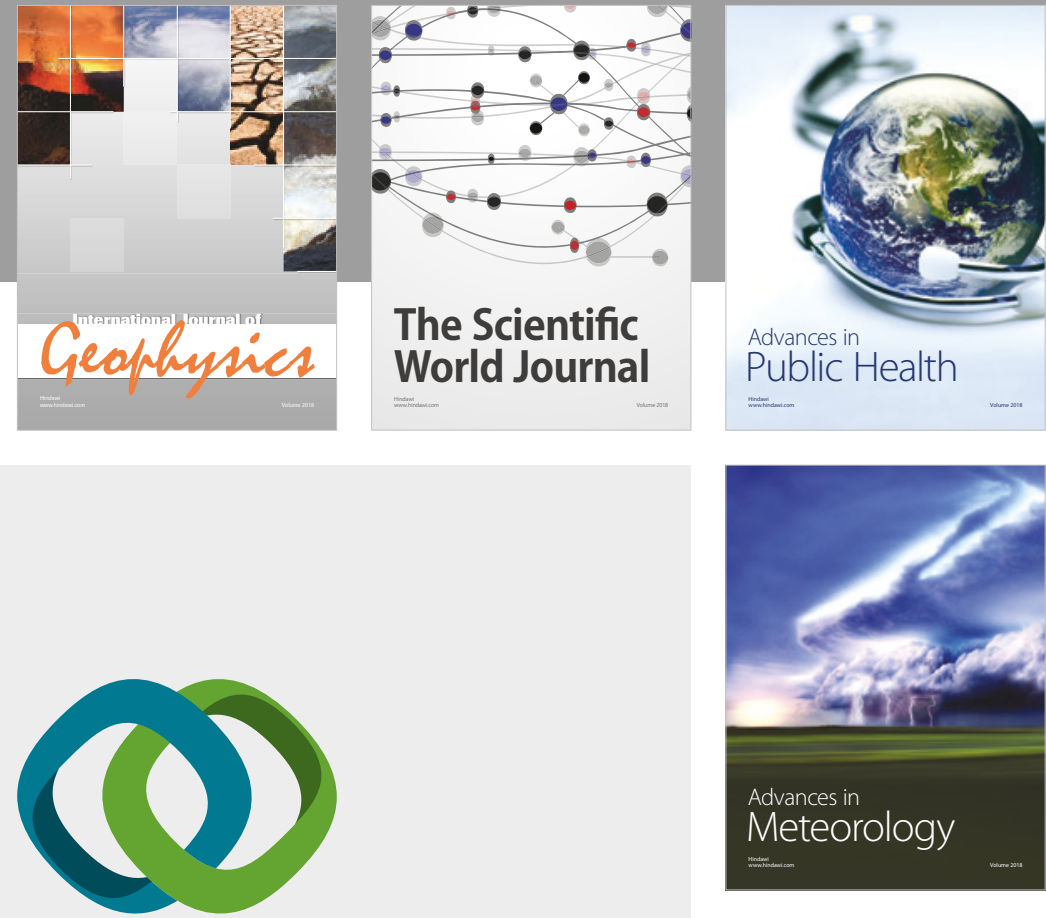

Advan

Public Health

\section{Hindawi}

Submit your manuscripts at

www.hindawi.com
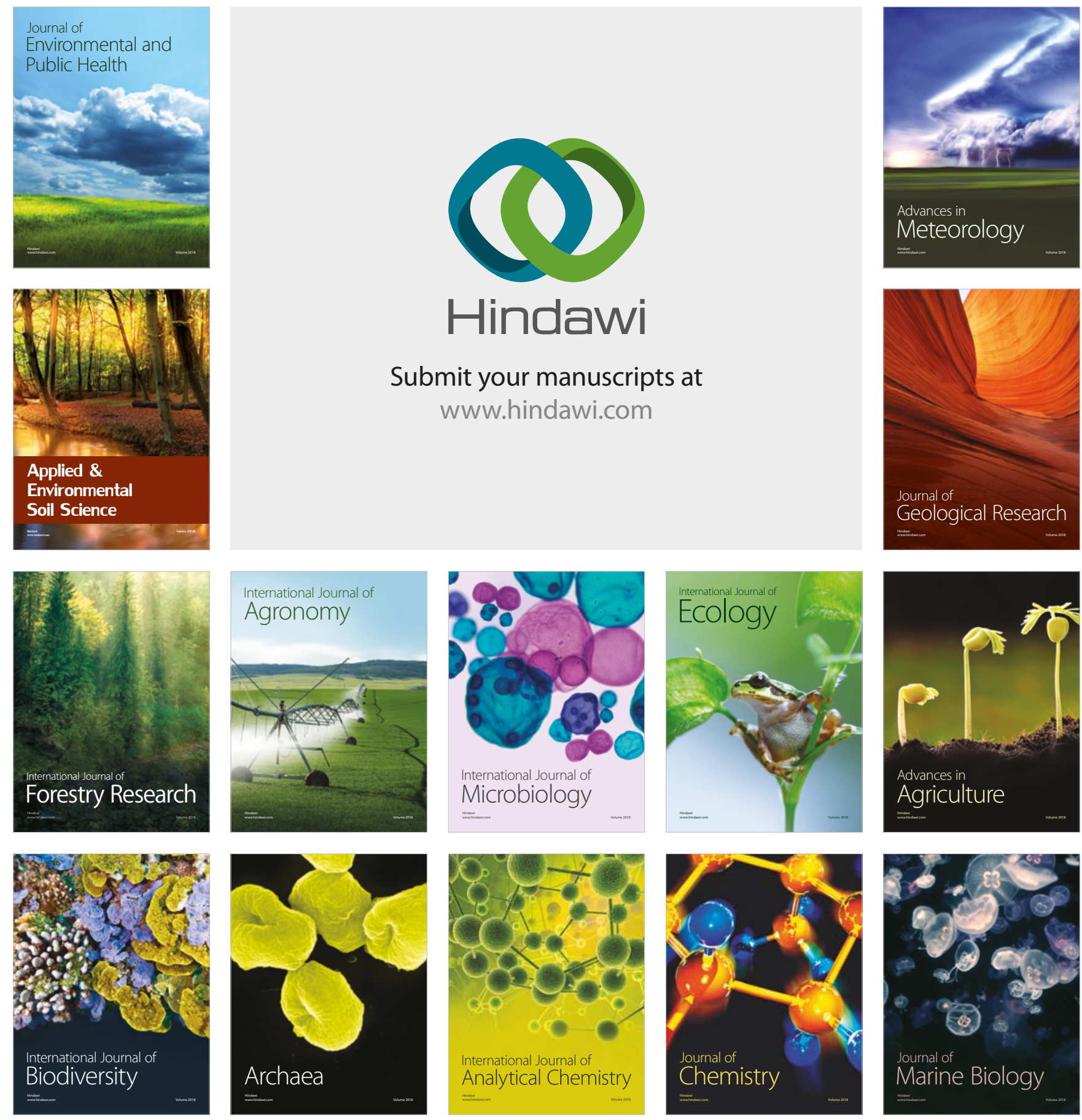